\title{
Developing an open geographic data model and analysis tools for disaster management: landslide case
}

\author{
A. C. Aydinoglu ${ }^{1}$ and M. S. Bilgin ${ }^{2}$ \\ ${ }^{1}$ Dept. of Geomatics Engineering, Gebze Technical University, Kocaeli, Turkey \\ ${ }^{2}$ Graduate Prog. of Geographic Information Technologies, Istanbul Technical University, Istanbul, Turkey \\ Correspondence to: A. C. Aydinoglu (arifcagdas@gmail.com)
}

Received: 11 July 2014 - Published in Nat. Hazards Earth Syst. Sci. Discuss.: 7 October 2014

Revised: - - Accepted: 1 February 2015 - Published: 24 February 2015

\begin{abstract}
Disaster management aims to reduce catastrophic losses of disasters. Geographic information technologies support disaster management activities for effective and collaborative data management considering the complex nature of disasters. This study with an original conceptual approach aims to develop interoperable geographic data model and analysis tools to manage geographic data sets coming from different sources. For landslide disaster, 39 scenario-based activities were analysed with the required data according to user needs in a cycle of activities at mitigation, preparedness, response, and recovery phases. An interoperable geographic data model for disaster management (ADYS), enabling upto-date exchange of geographic data, was designed, compliant with the standards of ISO/TC211 Geographic Information/Geomatics, Open Geospatial Consortium (OGC), and the Turkish National GIS (TUCBS). An open source and free analysis toolbox was developed and tested in the case study of activities such as landslide hazard analysis and a disaster warning system to support the Provincial Disaster Management Centres of Turkey. Open data models and analysis tools make effective activity management and data sharing possible. However, transforming data sets into data exchange formats is laborious.
\end{abstract}

\section{Introduction}

Disaster is a natural, manmade, or technological event which causes physical, economic and technological losses for the community and suspends the daily life of people with great destruction, ecological problems, loss of human life and deterioration of health (UNISDR, 2009; WHO, 2005; FEMA,
1990). Landslides, amongst the most damaging disasters in mountainous regions especially, cause loss of lives and affect the economy. In Turkey, the annual economic loss due to landslides is about USD 80 million, the the second most destructive natural disaster after earthquakes. The majority of the losses are in the eastern Black Sea region of Turkey which is subjected to heavy precipitation in mountainous topographical features (Yalcin, 2007; Ildir, 1995).

Disaster management aims to reduce potential losses, to provide essential assistance to victims, and to achieve rapid recovery. Disaster management works in a cycle of activities at mitigation, preparedness, response and recovery phases. Prior to disaster, mitigation phase activities analyse risks and reduce the possible impact of disasters, and then the preparedness phase activities plan to ensure a rapid and effective response. Response phase activities include emergency operations for minimizing effects during the disaster event and the recovery phase returns life to normal after the disaster (Orchestra, 2008; OASIS, 2005).

Geographic information systems (GISs) have an important role in effective disaster management. Considering the complex nature of disasters, GISs can manage base geographic data sets such as of buildings, roads and topography and realtime data sets such as of rainfall, earthquake and water flow. In the event of a disaster, actors and decision makers need upto-date, accurate and timely geographic data from different data providers. The data sets need to be used for collaborative decision making in disaster management activities. However, the lack of up-to-date exchange of the data sets hampers effective use of GIS in the activities. The delays and problems of access to qualified data affect decision processes in disaster management activities (Abdalla and Tao, 2005; Zhang et 
al., 2010). The availability of data sets is restricted by legal issues and limited by differences in data models and specifications (Aydinoglu and Yomralığlu, 2010).

In relation to GISs, the geospatial data infrastructure (GDI) as a framework encompasses policies, access networks, standards and human resources necessary for the effective management and the sharing of geographic data sets on web services. It provides a multi-participant environment for the actors to support decision making in disaster management activities (Mansourian et al., 2006; Molina and Bayarri, 2011). In this regard, data content standards supporting interoperability should be defined independently of any software and hardware for the successful functioning of the disaster management system. Otherwise, a system working with inconvenient data will be ineffective in the case of disasters (Aubrecht et al., 2013).

GIS is mostly implemented for generating hazard and risk maps of disasters by using spatial analysis tools and displaying maps in a web environment for planning purposes (Armenakis and Nirupama, 2013; Yalcin et al., 2011). As a part of national GDI initiatives, the Federal Geographic Data Committee (FGDC) Department of Homeland Security (DHS) has developed the DHS data model to support data interoperability in the disaster management community with allies (FGDC, 2009). Hazus is a national methodology that contains models for estimating potential losses from earthquakes, floods and hurricanes especially (Schneider and Schauer, 2006). The Geospatial Data Infrastructure for Disaster Management (GDI4DM) project develops open national data models to manage the preparedness and response phases for disasters. The Information Model for Safety and Security (IMOOV), compliant with other national data specifications of the Netherlands, provides a general approach for disaster or event management, similar to GDI4DM (Geonovum, 2008; Zlatanova et al., 2010). As well as these projects, integrated disaster management and developing data models compatible with national GDI are current research topics.

This study aims to determine an original conceptual model for harmonized and integrated disaster management. With regard to the conceptual model of disaster type/activity task/data relations applied to landslide case, this paper offers a method to develop open/general data specifications based on the requirements of all disaster management activities at different phases and to understand how open data sets can be analysed with open software tools. As the first application for the Turkish National GIS (TUCBS) infrastructure following the GDI vision, an interoperable data model for disaster management (ADYS) that makes possible the up-to-date exchange of geographic data sets from different sources was designed. ADYS analysis tools that are open, flexible and independent from any software and hardware were developed.

In Sect. 2, within the scope of the challenge of landslide disaster, the activities of the mitigation, preparedness, response and recovery phases that lead operations of the Dis- aster Management Centres in the provinces of Turkey are analysed. According to the standards of the ISO/TC 211 Geographic Information/Geomatics Committee, application schemas of the ADYS data model were designed with Unified Modeling Language (UML) and encoded to Geographic Markup Language (GML) data exchange format. For the activities in relation to landslides, an ADYS analysis toolbox requiring open geographic data sets was developed using open-source GIS software tools. In Sect. 3, these application schemas are tested in the case of activities such as landslide analysis, disaster warning system and disaster effect analysis. The effectiveness for disaster management is examined in the last sections.

\section{Material and methods}

A conceptual approach for disaster management is defined to cope with the complex nature of disasters. This approach helps to integrate management of disaster types such as earthquake, floods, landslides, fire and transportation accident. The activities at different phases of disaster management were analysed with required data to understand the requirements of the landslide case. As a result of this analysis, an open geographic data model for disaster management was designed and then open analysis tools were developed for the activities.

\subsection{Conceptual approach for disaster management}

The conceptual approach (Fig. 1) for disaster management was defined with upper classes; DisasterType, Actor, Activity, Task and Data (Aydinoglu et al., 2012);

- "DisasterType" defines disasters causing loss of life and property, such as landslide, earthquake and fire.

- "Activity" defines the applications to fight against the disasters at mitigation $(Z)$, preparedness $(H)$, response $(M)$ and recovery $(I)$ phases. For example, landslide risk analysis at mitigation phase, determining response units for fire at preparedness phase, determining earthquake effect area at response level, and restructuring works following flood at recovery phase are some examples of disaster management.

- "Actor" is responsible for managing the activities of any disaster type as S. Actor and works in response activities as F. Actor. The actors for example can be disaster management centres under the responsibility of governorships, civil defence, fire fighters, ambulance service and police. In addition to this, rescue teams and wreck removal units are actors responding to landslide hazard.

- "Task" is a part of the activity. Actors perform these tasks for the response activity of any disaster type such as registering an incident, directing a rescue team and evacuating an area. 


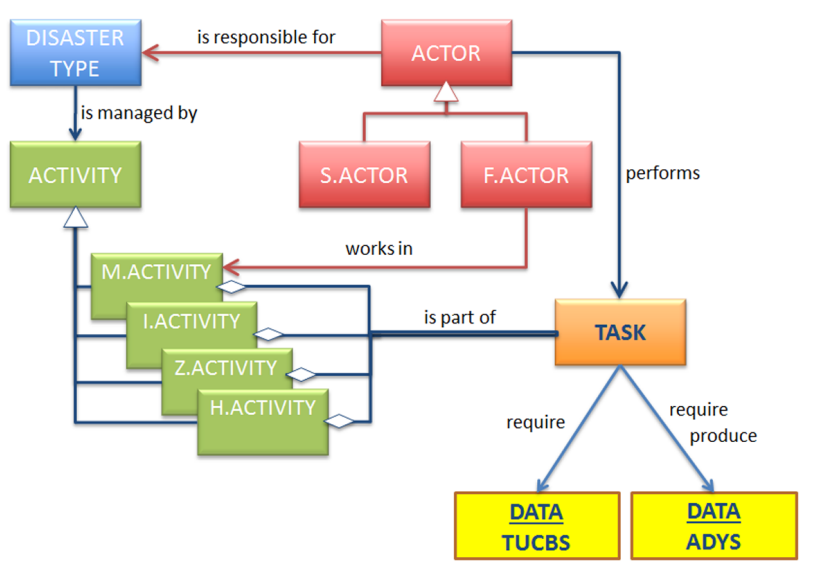

Figure 1. Conceptual model schema for disaster management.

- "Data" are required and produced during a task. It is supposed that a task requires existing data from the TUCBS base database and requires and produces static/dynamic data from the ADYS disaster management database.

\subsection{Activity analysis for landslide}

As a result of fieldwork in relation to the experts and the actors and by examining academic research, for the case of landslide, we defined 39 sub-activities of 15 activity groups within all disaster management phases (Aydinoglu et al., 2012). As well as landslide hazard and vulnerability analysis, often studied at mitigation phase, the activities at preparedness, response and recovery phases were also analysed.

As the first phase of disaster management, the mitigation phase contains the activities for the reduction of losses prior to disaster event. This phase consists of three parts; analysis, planning risk reduction and replanning (as seen on Table 1). HEY.Z.01 landslide analysis activities comprise works for determining landslide potential, risky buildings and infrastructures. HEY.Z.02 risk reduction activities contain works for the elimination and the reduction of risks determined in the analysis works. In HEY.Z.03 activity, residential areas are planned depending on landslide risk determined in landslide analysis works. GIS techniques were implemented in these activities to determine measures to be taken before landslides (INSPIRE, 2011; Muthukumar, 2013; Sudmeier et al., 2013; Holcombe et al., 2012; Jaiswal and van Westen, 2013).

As seen in Table 2, the preparedness phase as pre-disaster activity contains activities to determine and to coordinate resources during disaster. After determining landslide risk in the analysis activities, HEY.H.01 activity anticipates response areas when landslide occurs. While response units are planned in HEY.H.02 activities, resources in the response phase are examined in HEY.H.03 activities. HEY.H.04 activities estimate evacuation requirements when landslide oc-
Table 1. Landslide activities for the mitigation phase.

\begin{tabular}{ll}
\hline HEY.Z. & Landslide activities for mitigation phase \\
\hline HEY.Z.01 & Landslide analysis works \\
HEY.Z.01.01 & Landslide hazard analysis \\
HEY.Z.01.02 & Landslide vulnerability analysis \\
HEY.Z.01.03 & Landslide risk analysis \\
HEY.Z.02 & Planning landslide risk reduction \\
HEY.Z.02.01 & Regulating natural slopes \\
HEY.Z.02.02 & Identifying areas for the barrier \\
HEY.Z.02.03 & Improving the ground of the slopes \\
HEY.Z.02.04 & Reforestation of the slopes \\
HEY.Z.02.05 & Establishment of drainage systems \\
HEY.Z.02.06 & Determining areas for the construction of retaining walls \\
HEY.Z.02.07 & Strengthening the buildings \\
HEY.Z.03 & Landslide re-planning \\
HEY.Z.03.01 & Planning new construction areas \\
HEY.Z.03.02 & Making changes in plans \\
\hline
\end{tabular}

Table 2. Landslide activities for the preparedness phase.

\begin{tabular}{ll}
\hline HEY.H. & Landslide activities for preparedness phase \\
\hline HEY.H.01 & Planning landslide response \\
HEY.H.01.01 & Determining response areas \\
HEY.H.02 & Determining response units \\
HEY.H.02.01 & Determining police response units \\
HEY.H.02.02 & Determining fire response units \\
HEY.H.02.03 & Determining health response units \\
HEY.H.02.04 & Determining civil defence units \\
HEY.H.02.05 & Determining emergency management units \\
HEY.H.03 & Determining response resources \\
HEY.H.03.01 & Determining locations for food and clothing supplies \\
HEY.H.03.02 & Determining locations for health supplies \\
HEY.H.03.03 & Determining locations for appliance supplies \\
HEY.H.04 & Planning evacuation \\
HEY.H.04.01 & Landslide evacuation analysis \\
HEY.H.04.02 & Determining evacuation staff \\
HEY.H.05 & Landslide warning system \\
HEY.H.05.01 & Determining locations for warning system \\
\hline
\end{tabular}

curs. It is established prior to a disaster which buildings may be damaged and should be evacuated. In this way, these activities help to rescue people in the disaster effect area quickly. HEY.H.05 activity determines locations for the disaster warning system. These outputs are used in the activities of the response phase (Bittencourt et al., 2013; Venkatesan et al., 2013; Ko and Kwak, 2012).

Response activities include tasks immediately after disasters as seen in Table 3. HEY.M.01 activity determines the affected area after a disaster has occurred and its location is defined. Affected buildings and infrastructure are determined in the HEY.M.02 activity, important for response units and the evacuation process of victims. HEY.M.03 activity directs response units such as police, health response and civil defence by using network analysis functions of GIS. While HEY.M.04 activity identifies buildings for evacuation, HEY.M.05 activity delivers basic and health supplies determined in the preparedness phase (HS, 2008; Saadatseresht et al., 2009; Keim, 2008). 
Table 3. Landslide activities for the response phase.

\begin{tabular}{ll}
\hline HEY.M. & Landslide activities for response phase \\
\hline HEY.M.01 & Determining disaster effect area \\
HEY.M.01.01 & Defining disaster location \\
HEY.M.02 & Disaster effect analysis \\
HEY.M.02.01 & Determining affected buildings \\
HEY.M.02.02 & Determining affected infrastructures \\
HEY.M.03 & Directing response units \\
HEY.M.03.01 & Directing police response units \\
HEY.M.03.02 & Directing fire response units \\
HEY.M.03.03 & Directing health response units \\
HEY.M.03.04 & Directing civil defence units \\
HEY.M.03.05 & Directing emergency management units \\
HEY.M.04 & Evacuations works \\
HEY.M.04.01 & Identifying buildings for evacuation \\
HEY.M.04.02 & Routing evacuation \\
HEY.M.05 & Delivery of help resources \\
HEY.M.05.01 & Delivery of base and health supplies \\
\hline
\end{tabular}

The recovery phase includes activities for the reduction and elimination of disaster losses. As seen in Table 4, HEY.I.01 activity detects debris and plans debris removal by defining convenient location and logistics facilities. HEY.I.02 activity plans new settlements to update zoning plans after the disaster has brought about destruction. Thus, risk reduction and elimination will be provided in the long term (Beck, 2005; Wiles et al., 2005).

\subsection{Requirement analysis example for landslide activities}

Each activity has various tasks respectively that were managed by the actors. These tasks need static and real-time geographic data. Base data sets such as buildings, roads and topography are included in the static data category. Meteorological data, earthquake data, and traffic density data can be defined in the real-time data category.

For landslide disaster, the sub-activities were analysed to establish the data requirements. These analyses were carried out based on expert opinion after examining academic publications and projects, and then completed with the assessment of actors in the disaster management sector. The data requirement analysis defines produced and used geographic data sets with detailed information including data types, geometry, attributes and values, associations and topological rules, and possible functions.

For example, in the mitigation phase, HEY.Z.01.01 Landslide Hazard Analysis produces landslide hazard raster data sets by using spatial analysis techniques on data sets such as topography, land cover, stream, road and lithology. Topography, for example, with line geometry was defined with attributes such as elevation height, type and accuracy.

In the response phase, HEY.M.O3.05 Directing Emergency Management Units as a sub-activity of HEY.M.03 Di-
Table 4. Landslide activities for the recovery phase.

\begin{tabular}{ll}
\hline HEY.I. & Landslide activities for recovery phase \\
\hline HEY.I.01 & Recovery in disaster area \\
HEY.I.01.01 & Detection of debris \\
HEY.I.01.02 & Planning for debris removal \\
HEY.I.02 & Restructuring works \\
HEY.I.02.01 & Detecting restructuring regions \\
HEY.I.02.02 & Making changes in the environmental plan \\
\hline
\end{tabular}

recting Response Units produces transportation route data sets by using GIS network analysis techniques. The tasks in this analysis require response area, road, emergency response unit, affected building and response source data sets. Response source location, as an example, with point geometry was defined with the attributes such as emergency response material list, material amount, responsible person and communication information.

\subsection{Designing an interoperable geographic data model of Turkey for the landslide case}

Disaster management projects in Turkey were initiated after the devastating Marmara earthquake in 1999. The Turkish Disaster Information System (TABİS) project developed a database structure and GIS standards for disaster management. These standards were implemented for Istanbul in a project (Bilgi et al., 2008). The Hazturk project based on Hazus developed an earthquake loss estimation for Turkey. Various other projects have been instigated, such as a meteorological early warning system, seismic risk mitigation, emergency transportation network planning, and disaster information system projects especially focused on earthquake (Korkmaz, 2009). In 2009, the Prime Ministry of Turkey established a Disaster and Emergency Management Presidency according to the law N.5902, aiming to coordinate all disaster events under a central administration structure, and with provincial administrations responsible for managing disaster events (Gazette of Republic of Turkey, 2009). However, the data management and coordination approaches have not been determined yet in relation to disaster types, actors and disaster activities (Aydinoglu et al., 2011; Erden, 2012).

The Turkish National GIS (TUCBS) base data specifications were designed to enable geographic data interoperability between data providers and users, after the General Directorate of GIS was established in 2012. However, TUCBS data models have not been put into practice yet and stakeholders have met with problems such as the usability of data models, data sharing problems, and repetitive data production. Data interoperability is required between sector data models such as disaster management and national data models like TUCBS (GDGIS, 2012a).

In this study, the ADYS data model used as disaster management data model was designed for the landslide case 


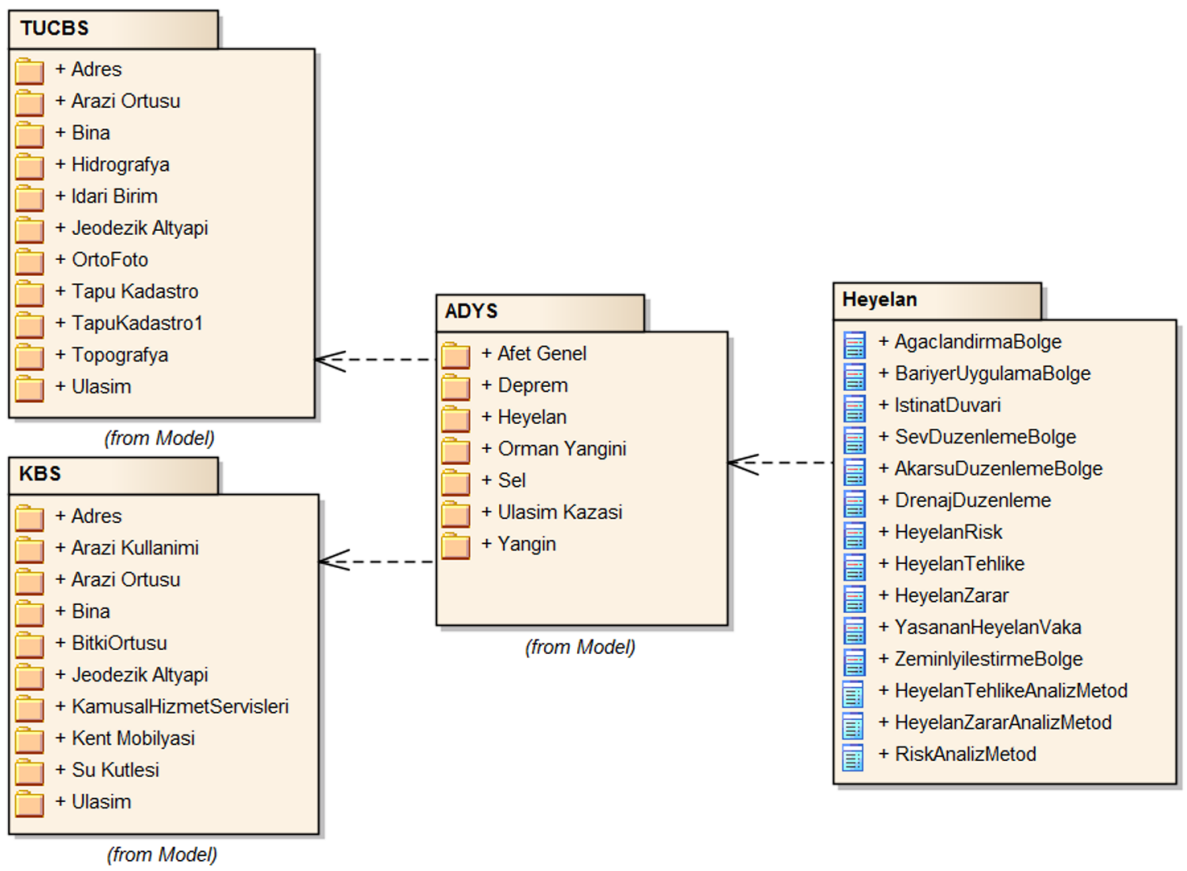

Figure 2. Data themes in TUCBS, KBS and ADYS data models and feature types in the landslide theme.

according to the data requirement in the activity analysis. In conceptual approach, the ADYS data model is compliant with TUCBS and Urban GIS (KBS) data models. TUCBS base data themes such as Address (AD.Adres), Land Cover (AO.Arazi Örtüsï), Building (BI.Bina), Administrative Unit (IB.Idari Birim), Hydrography (HI.Hidrografya), Geodesy (JD.Jeodezik Altyapı), Orthophoto (OR.Ortofoto), Land Registry-Cadastre (TK.Tapu-Kadastro), Topography (TO.Topografya), and Transportation (UL.Ulaşım) are used as base static data in disaster management activities (GDGIS, 2012b). It is supposed that data interoperability will be possible at the logical level because public institutions have accepted TUCBS standards for the exchange of geographic data sets (Fig. 2).

ADYS is an object-oriented geo-data model. ISO 19103 Conceptual Schema Language (ISO/TC211, 2005a), ISO 19109 Application Schema Rules (ISO/TC211, 2005b), and other related standards of ISO/TC211 define rules to model feature types, relations between these, attributes, geometries and other properties. The modelling language UML is used for object modelling.

The ADYS data model includes feature types defined in the disaster management activities for the disaster types like Earthquake (Deprem), Landslide (Heyelan), Flooding (Sel), Forest Fire/Fire (Orman/Kent yanginı), Transportation Accident (Ulaşım Kazası), and disaster general (Afet Genel). This model includes disaster-related feature types not defined in TUCBS and KBS data models. For example, beside other geo-data themes, the landslide theme includes feature types; plantation area (AgaclandirmaBolge), barrier area (BariyerUygulamaBolge), retaining walls (IstinatDuvari), slope regulation region (SevDüzenlemeBölge), drainage arrangement (DrenajDuzeneleme), landslide hazard (HeyelanTehlike), and so on.

According to the requirement analysis of landslide activities, the used and produced feature types were modelled for the activities. For example:

In the activity HEY.Z.01 Landslide Analysis Works as seen in Fig. 3, HEY.Z.01.01 requires digital elevation model, slope and aspect ("featuretype" YukseklikGrid, Egim, Baki) from TUCBS.TO, stream ("featuretype" Akarsu) from TUCBS.HI, land cover ("featuretype" AraziOrtusuNesnesi) from TUCBS.AO, road ("featuretype" Karayolu) from TUCBS.UL, and lithology ("featuretype" Litoloji) from TUCBS data themes. Landslide hazard ("featuretype" HeyelanTehlike) of the ADYS data model is produced by analysing these inputs according to the method.

HEY.Z.01.02 requires building ("featuretype" Bina) from TUCBS.BI, transportation base class ("featuretype" Ulasim) from TUCBS.UL, infrastructure base class ("featuretype" Ulasim) from TUCBS data themes. According to the method, landslide vulnerability ("featuretype" HeyelanZarar) of the ADYS data model is produced by analysing these inputs.

A risk zone is the spatial extent of a combination of a hazard and the associated probability of its occurrence. A risk zone must be associated with one or more vulnerability coverage including exposed elements such as building and infrastructure (INSPIRE, 2011). For HEY.Z.01.03, landslide risk ("featuretype" HeyelanRisk) of the ADYS data model 


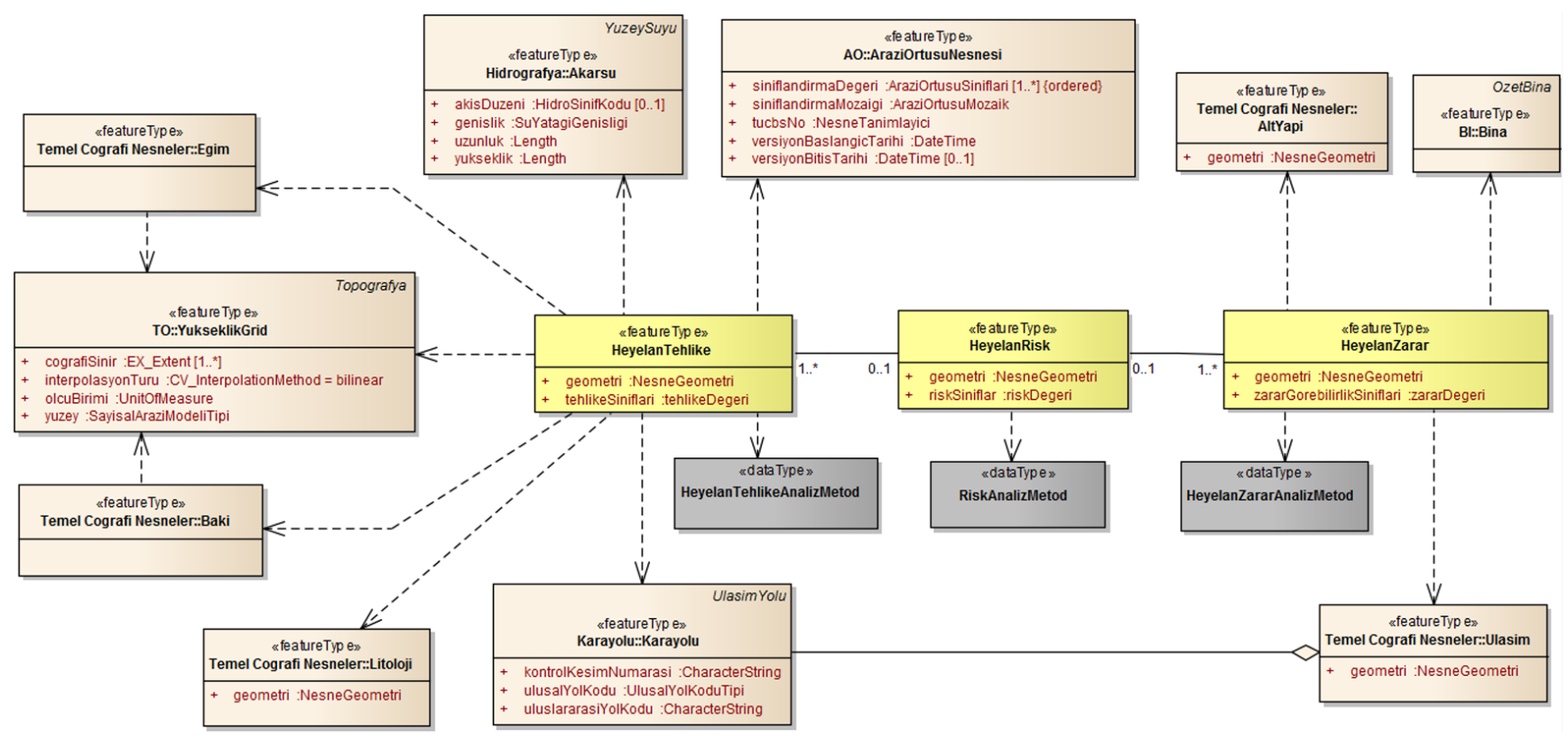

Figure 3. Relations between hazard, vulnerability and risk feature types.

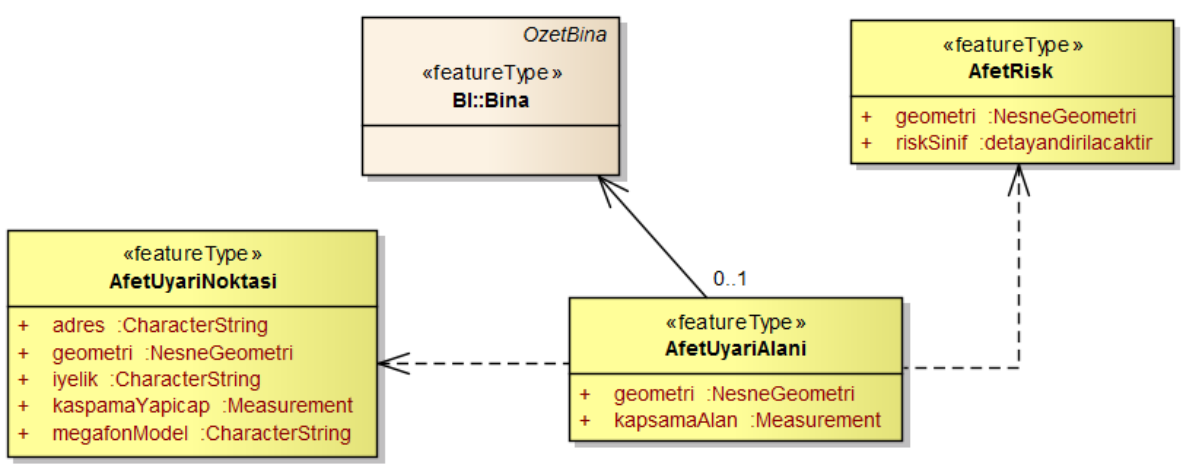

Figure 4. ADYS feature types concerning a disaster warning system.

is associated with a landslide hazard when landslide hazard is in vulnerability feature types.

In the activity HEY.H.05 Landslide Warning System, required data are Building ("featuretype" Bina) from TUCBS.BI and Disaster Risk ("featuretype" AfetRisk) from the ADYS general data theme. Disaster warning area (" $\mathrm{fea}$ turetype" AfetUyarı Alanı) depending on disaster risk and disaster warning point ("featuretype" AfetUyariNoktasi) feature types are defined with address, geometry, ownership, and megaphone model attributes in the ADYS data model (Fig. 4).

HEY.M.01 Determining Disaster Effect Area is the first activity in the response phase to identify areas where the disaster occurs and to determine affected structures. Figure 5 presents feature types of this activity defined in the ADYS model. The location of the disaster is defined in event ("featuretype" Olay) feature type with point geometry. If an event covers a wide area and threatens human life and the environment, a disaster is declared and the estimated disaster effect area ("featuretype" TahminiAfetEtkiAlani) is defined with polygon geometry.

After response units have commenced work, the actual impact of the disaster is defined by the disaster effect area ( $\mathrm{fea}$ turetype" AfetEtkiAlani). This area aggregates affected buildings, infrastructures, transportation and vehicle feature types that are inherited from the TUCBS data model. Response areas ("featuretype" MudahaleBolgesi) are determined and response units are directed to the structures in the disaster effect area.

\subsection{Approach for geographic data exchange}

After modelling UML application schemas, these models were transformed to ISO 19136 Geography Markup Language (GML) format that is an XML-based encoding stan- 


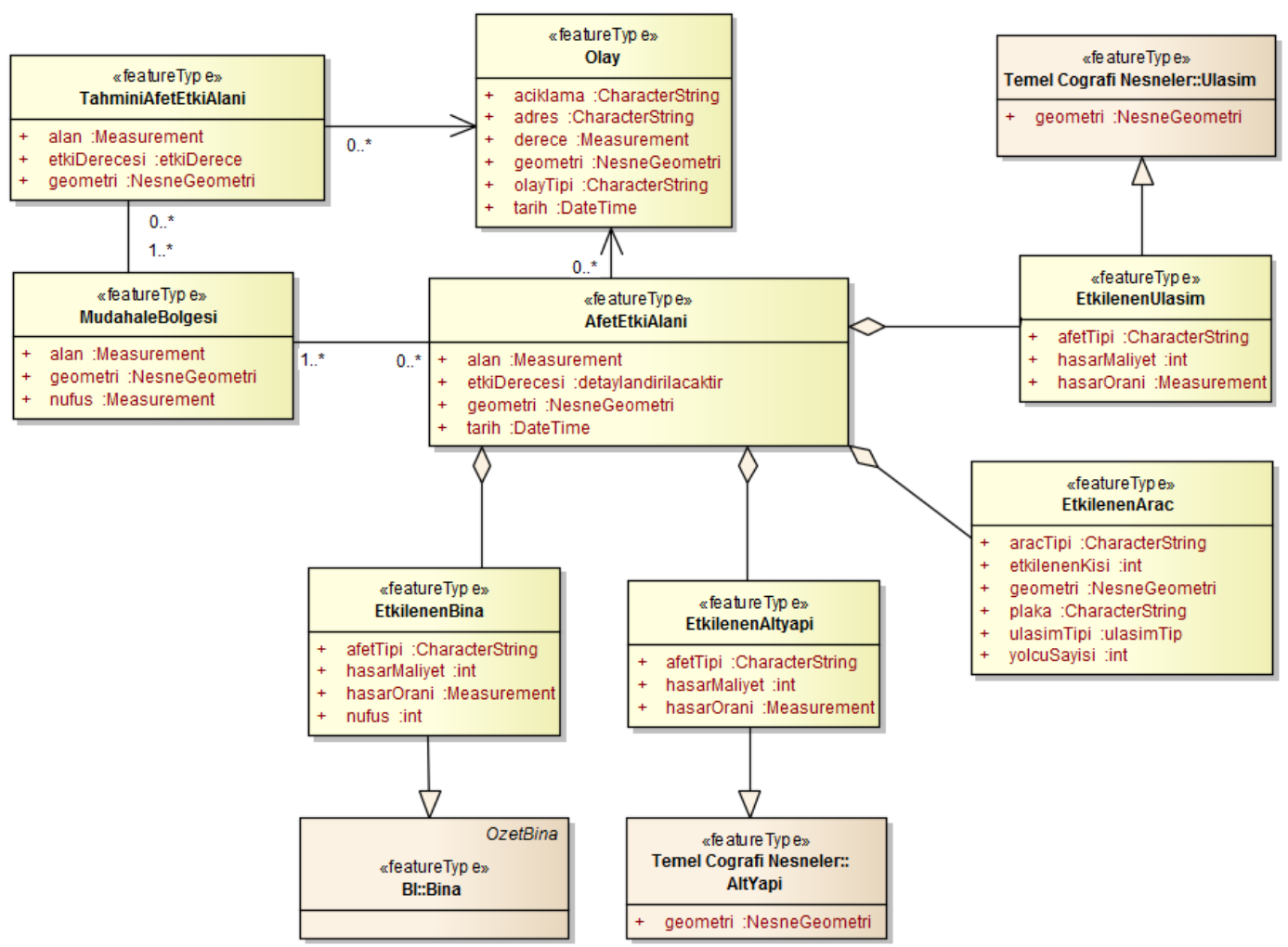

Figure 5. ADYS feature types concerning disaster effect analysis.

dard for geographic data interoperability developed by the Open Geospatial Consortium (OGC). It is supposed if different geographic data sets produced by different users are converted into the TUCBS and ADYS data exchange format, these data sets can be used in the disaster management activities effectively (OGC, 2011, 2012; Li et al., 2008). Geographic data sets, therefore, should be transformed from one system to another by using these application schemas as data exchange format.

However, public institutions get used to work with their familiar software and database environment. The ExtractTransform-Load (ETL) tool, therefore, was developed to overcome interoperability challenges by providing accurate and defined geographic data sets to the users. The ETL tool extracts data from a source database, transforms the data to the format defined in TUCBS and ADYS application schemas, and loads the data into the application database for disaster management activities.

\subsection{Developing open spatial analysis tools for the activities}

Free and Open Source Software (FOSS) desktop GIS programs were used to develop the ADYS toolbox since most GIS functions can be accomplished in desktop environment. Quantum GIS, GRASS GIS and SAGA GIS as mature desktop GIS projects were used in this study. These are licensed by General Public License (GPL) and free alternatives to commercial software (Steiniger and Hunter, 2013; Teeuw et al., 2013).

Processing steps of the analysis tools were developed in the Quantum GIS (QGIS) open source platform. QGIS performed extremely well under the existing conditions and its functionalities are adequate for general applications. As user interface of the ADYS toolbox, the Sextante toolbox is a Java-based framework and processes vector and raster data with several desktop GIS tools. Its functionalities can be enhanced with GIS functions of other programs (Chen et al., 2010; Hugentobler, 2008).

GRASS GIS has become a high-quality cutting edge GIS, represents a collaborative development model, and supports the free spread of knowledge. Users are encouraged to download the underlying code, and to customize and enhance all algorithms and methods. Since it is a modular system it may be implemented in various environments (Neteler et al., 2012; Steineger and Hay, 2009; Neteler and Mitasova, 2008; Casagrande et al., 2012).

Beside these, the System for Automated Geoscientific Analysis (SAGA GIS) has emerged with powerful and various spatial analysis tools (Cimmery, 2010; Conrad, 2007). GDAL (raster) and OGR (vector) are two libraries that import and convert between different geographic data formats. 


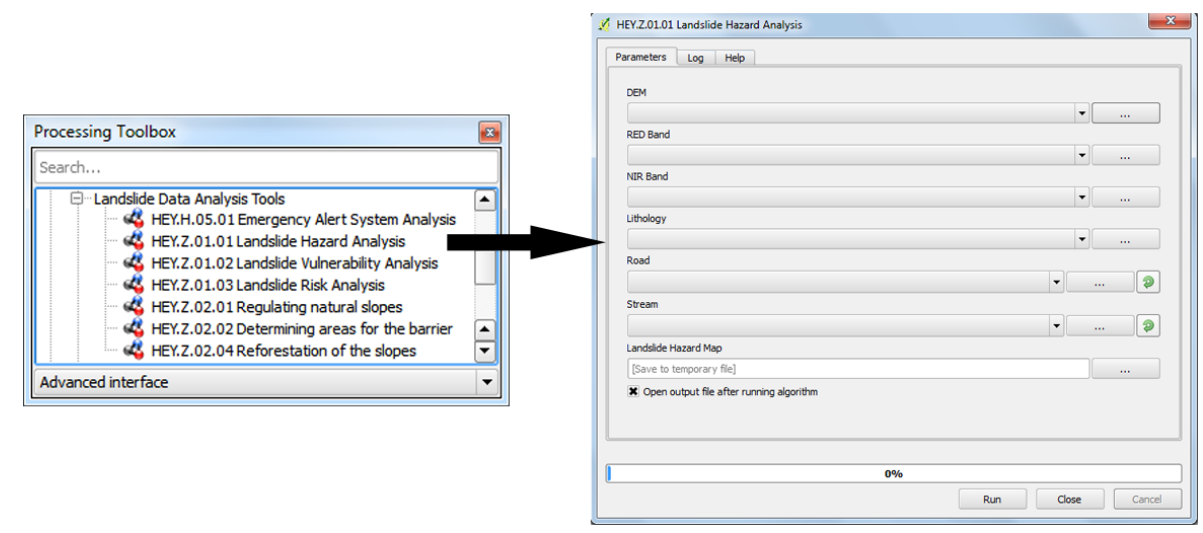

Figure 6. ADYS analysis toolbox and user interface of HEY.Z.01.01 activity.

Their Python bindings play a significant role in current FOSS developments.

The ADYS analysis toolbox was developed to manage landslide activities according to the activity analysis explaining task steps. The framework provides templates for the custom construction of model components arranging the schedule of the integrated model. The high-level Python language, allowing for domain experts without in-depth knowledge of software, was used for model construction of the activities (Schmitz et al., 2013).

Figure 6 shows the ADYS toolbox including landslide activities as an example. As the activities of mitigation phase, HEY.Z.01.03 Landslide Risk Analysis tool can be run after HEY.Z.01.01 Landslide Hazard Analysis and HEY.Z.01.02 Landslide Vulnerability Analysis tools. These tools use input GML data sets from the TUCBS database as explained in Fig. 3. GRASS GIS and SAGA GIS functions were utilized in the processing steps of this tool as seen in Fig. 8. Besides r.slope.aspect for generating slope and aspect and r.buffer for creating a raster Euclidean distance from GRASS GIS; shapes to grid, reclassify grid values and raster calculator were used from SAGA GIS.

In the HEY.Z.01.01 tool, the raster calculator is used to produce a landslide hazard map ("featuretype" Heyelan Tehlike) from the input data sets. The Analytic Hierarchy Process (AHP) improved by Saaty (1980), one of the multicriteria decision analyses (MCDA), deals with complex decision making and help to determine the weights of selected criteria for each input data set (Saaty and Vargas, 2001; Chen et al., 2013; Erden and Karaman, 2012). A pair-wise comparison matrix, factor weights and consistency ratio of the data sets were determined after reviewing academic publications, Yalcin et al. (2011) especially.

Figure 7 shows the Python code of processing steps for the activity HEY.H.05.01 disaster warning system. This activity requires GML data sets from the TUCBS database and aims to define warning points and the covered area in the best way. The location of warning points should be the opti- mum number - covering more population depending on effect area. Thus, open analysis functions such as creategraticule from SAGA GIS, polygoncentroids, extractnodes and fixeddistancebuffer from QGIS, and v.select from GRASS GIS were used.

\section{Case study}

The activity tools of HEY.Z.01.01 Landslide Hazard Analysis and HEY.Z.01.02 Landslide Vulnerability Analysis were tested to produce HEY.Z.01.03 Landslide Risk Analysis. Data sets defined in Fig. 3 were collected from various public institutions for Macka county of Trabzon province in Turkey, such as elevation and stream data sets from the General Command of Mapping (GCM), transportation data sets including road from the Ministry of Transportation, a lithology data set from General Directorate of Mine Research, infrastructure and building data sets from local government, and LANDSAT imagery.

By designing the ETL tool developed in FME software, these data sets were converted to the GML-based data exchange format of TUCBS and ADYS and then to the applicable database format because of different formats and contents.

For Landslide Hazard Analysis, the HEY.Z.01.01 tool use digital elevation model (DEM), lithology, stream, road, and satellite image (Fig. 8). Processing steps with additional analysis tools were as follows:

- All input data sets were converted to raster format for analysis processes.

- Using surface analysis techniques produces slope and aspect data sets ("featuretype" Egim/Baki) from digital elevation data sets ("featuretype" YukseklikGrid).

- Calculating the Normalized Difference Vegetation Index (NDVI) in red and near-infrared (NIR) bands of 


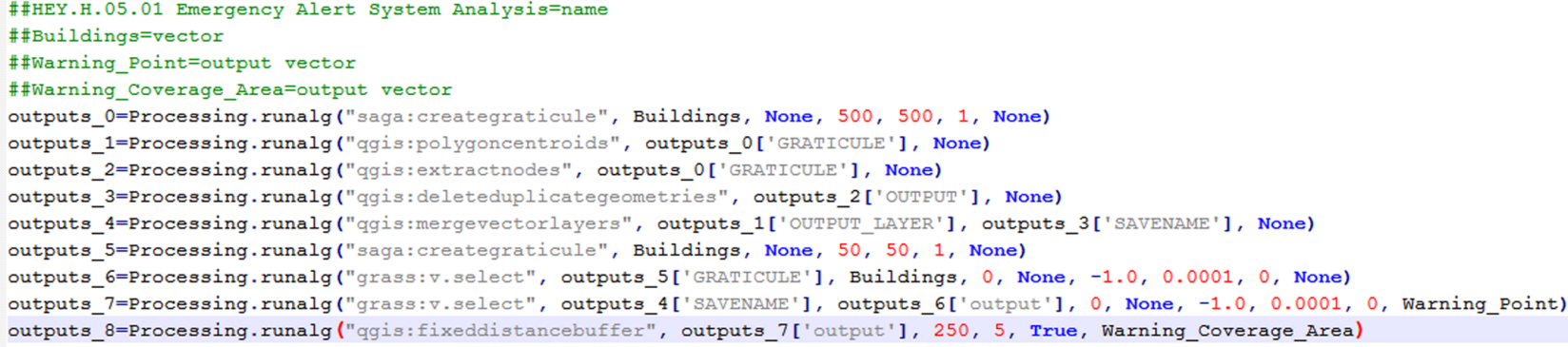

Figure 7. Processing steps of HEY.H.05.01 activity.

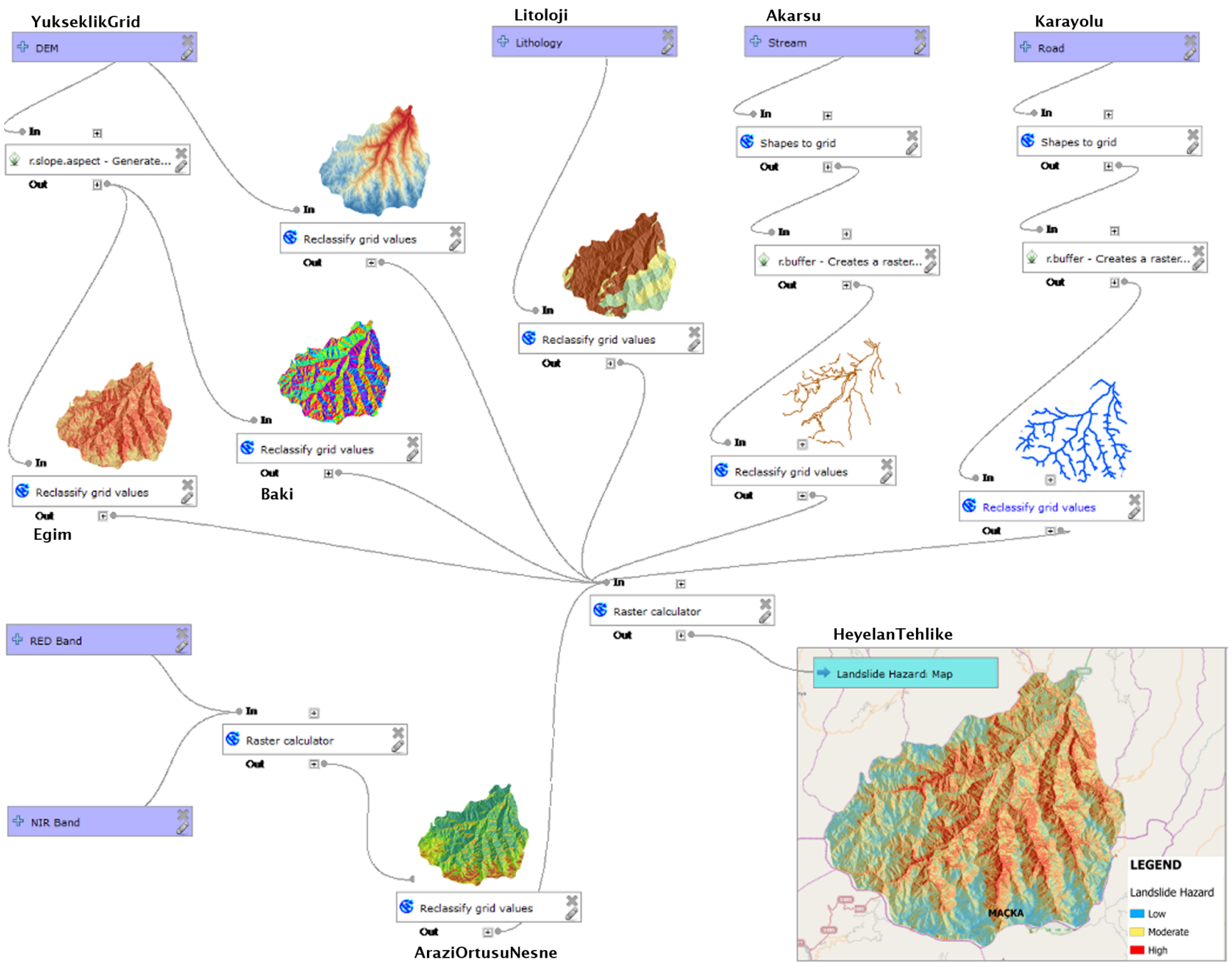

Figure 8. Processing steps and data sets for landslide hazard analysis in Macka, Trabzon, Turkey.

satellite imaging determines vegetation as land cover object ("featuretype" AraziOrtusuNesnesi).

- Using a Euclidean distance analysis tool produces distance to road and stream data sets from base data sets ("featuretype" Karayolu/Akarsu).
- Reclassifying raster data sets determines normalized factor weights for lithology, slope, aspect, land cover, elevation, distance to stream, and distance to road. For example, factor weights of slope are 0.043 for 0 $10 \%, 0.068$ for $10-20 \%, 0.123$ for $20-30 \%, 0.288$ for $30-50 \%$ and 0.479 for bigger than $50 \%$ (consistency 


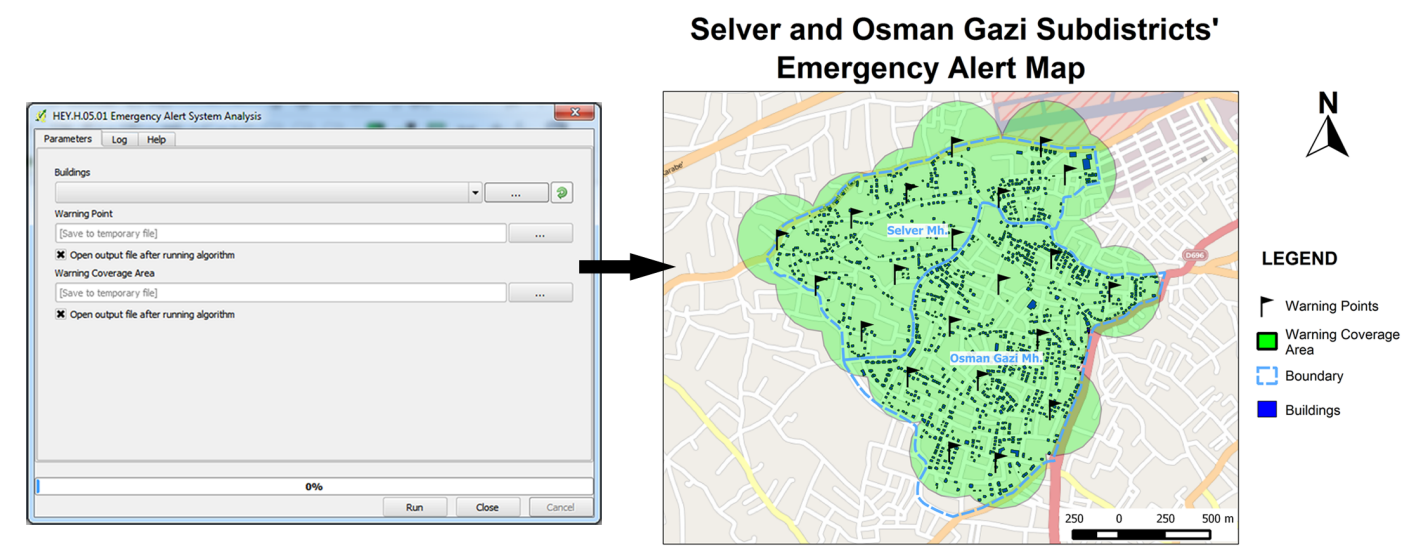

Figure 9. User interface and data sets produced for disaster warning system in Meram, Konya, Turkey.

ratio: 0.038). Factor weights of distance to road are 0.394 for $0-25 \mathrm{~m}, 0.234$ for $25-50 \mathrm{~m}, 0.124$ for 50 $75 \mathrm{~m}, 0.124$ for $75-100 \mathrm{~m}$, and 0.124 for $100-125 \mathrm{~m}$ (consistency ratio: 0.016).

- The last process of this tool analyses the data sets by a weighted linear combination (WLC) method depending on the weight values of each factor. Weight values between the factors were calculated as 0.386 for lithology, 0.230 for slope, 0.129 for aspect, 0.098 for elevation, 0.083 for land cover, 0.037 for distance to stream and 0.037 for distance to road (consistency ratio: 0.038 , acceptable).

- As a result, the Landslide Hazard Map ("featuretype" HeyelanTehlike of ADYS) was produced with low, medium, and high hazard level as seen in Fig. 8.

For Landslide Vulnerability Analysis, the HEY.Z.01.02 tool uses building data sets, infrastructure data sets including linear engineering structures, and transportation data sets including road, railway and related structures. Similar to the processing steps above, these data sets were analysed by WLC method depending on the weight values of each factor. As a result of this case study, vulnerable areas ("featuretype" HeyelanZarar) of ADYS were determined for analysis with the landslide hazard map.

To test the HEY.H.05.01 activity tool, Selver and Osman Gazi Districts of Meram county of Konya province of Turkey were determined as case area. The input building data set was collected from local government and analysed by using the interface in Fig. 9. The processing steps are defined in Fig. 7:

- Graticule was created with $500 \mathrm{~m}$, depending on building data sets. Centroids and nodes were extracted from graticule. Duplications were eliminated and then the data were merged.

- Graticule was created for building area again. Warning points were selected in these areas. Then, the covered area was defined with the buffer function.
- After the processing steps of this analysis tool, it is supposed that each warning point represents an area of $250 \mathrm{~m}$. As output of this tool, GML data sets of disaster warning points ("featuretype" AfetUyariNoktasi) and disaster warning area ("featuretype" AfetUyariAlani) were produced in the ADYS database.

- As a result, 21 disaster warning points covering $97.3 \%$ of buildings were assigned by using this analysis tool.

\section{Results}

The ADYS disaster management data model was designed as an open and object-oriented geographic data model compatible to ISO/TC211 standards and national data models. It is supposed that if data providers produce geographic data sets depending on these data models, data sharing and cooperation will be possible between actors for disaster management activities at mitigation, preparedness, response and recovery phases. This model, therefore, is a new approach for geographic data interoperability in Turkey.

The ADYS data model with landslide case can be implemented in any geographic database because it was designed independently of any software and hardware. In general, accepted and familiar methods have been determined for each activity because the model was prepared according to analysis results of the activities and the background of available projects. Thirty-nine activities at all disaster management phases of landslide can be managed with this approach and it represents a new approach for integrated disaster management in the public institutions.

Using a standardized geo-data model provides the interoperability of geographic data sets. GML data sets were used and produced in open data exchange format in the case study. However, an intensive process was required to collect the data sets coming from different sources, to convert to the open data model defined, and then to make usable in any database environment. A new data conversion is required for 
each activity because the source data sets have not been standardized yet in Turkey. If each public institution had shared the data sets according to the standard of TUCBS and ADYS model, these open data sets could have been used in the activities automatically.

ADYS activities such as landslide analysis applications and disaster warning systems were tested with developed open-source analysis tools. This modeller environment of QGIS provides opportunities for using various open source software tools in the processing steps of the same activity. Multi-criteria decision analysis techniques and tools were implemented in the activities, aiming to compose an automated analysis system. Compared with commercially available software, open source functions and tools tested with the case study can be used in the disaster management activities and provide accurate results.

In this way, using these analysis tools with open geographic data sets provide costless and improvable solutions for the landslide activities of Disaster Management Centres in any province of Turkey.

\section{Discussion}

Disaster management is a multi-disciplinary activity. The most fundamental asset is the data itself that needs to be shared between different actors. It is important to reach real and accurate geographic data sets on time. Geographic data sets used by actors have great importance in performing the tasks of the activities at different phases of disaster management. Therefore, the ADYS conceptual model can be accepted as a practical approach for integrated management of different disaster types like landslide.

Building GDI, named as TUCBS in Turkey, provides tools giving easy access to distributed databases for disaster management actors who need data sets for their own activities. Activities with tasks were formalized sequentially while the required data for each task were obtained from the TUCBS mechanism compliant with the ADYS model.

It will be possible to manage and to use dynamic geographic data on electronic communication networks when the web interface developed with the Service Oriented Architecture (SOA) is configured on web and data servers. Related stakeholders can manage and update geographic data at a place where the data is maintained effectively. It is supposed that web services can have their interfaces generated automatically from the models. That is, UML-specified interfaces should be translatable into the specifications written in the Web Services Description Language (WSDL).

On the other hand, each GIS system works independently and can communicate with each other using agreed standards and exchange format. Even if TUCBS is implemented, this study will have some disadvantages relating to model conversion from UML to GML. This model-driven conversion causes the loss of some modelling content. The model, there- fore, should be kept as simple as possible for consistency of the data exchange format, avoiding complex systems and databases. In this study, most of these problems were tested and eliminated by making reasonable changes.

Open source ADYS software tools can be implemented to develop complex analysis for different activities. These analysis tools are open source so users can modify them for their applications. However, expertise is required to build and manage open source tools. Eliminating bugs takes time when compared with commercial GIS software.

Acknowledgements. A. C. Aydinoglu is grateful to the Scientific and Technological Research Council of Turkey (TUBITAK) for funding his 109Y342 numbered research project, ADYS titled as "Developing Map-support System for Disaster Management with Geographic Information Systems".

Edited by: R. Lasaponara

Reviewed by: two anonymous referees

\section{References}

Abdalla, R. and Tao, V.: Integrated distributed GIS approach for earthquake disaster modeling and visualization, in: GeoInformation for Disaster Management, edited by: van Oosterom, P., Zlatanova, S., and Fendel, E. M., Springer-Verlag, Berlin, Heidelberg, 1183-1192, 2005.

Armenakis, C. and Nirupama, N.: Estimating spatial disaster risk in urban environments. Geomat. Nat. Hazards Risk, 4, 289-298, 2013.

Aubrecht, C., Fuchs, S., and Neuhold, C.: Spatio-temporal aspects and dimensions in integrated disaster risk management, Nat. Hazards, 68, 1205-1216, 2013.

Aydinoglu, A. C. and Yomralıoğlu, T.: Harmonized GeoInformation Model for Urban Governance, Proc. Inst. Civ. Eng. Municip. Eng., 163, 65-76, 2010.

Aydinoglu, A. C., Demir, E., and Yomralioglu, T.: An Approach to Use Geo-Information Effectively in Disaster \& Emergency Management Activities in Turkey, FIG Working Week 2011, Marrakech, Morocco, 2011.

Aydinoglu, A. C., Yomralioglu, A. C., and Karaman, H.: Developing Map-support System for Emergency Management with Geographic Information Systems, Final Report of Research Project, No:109Y342, Tubitak Caydag, Ankara, 2012.

Beck, T.: Learning Lessons from Disaster Recovery: The Case of Bangladesh, World Bank, Washington, D.C., 2005.

Bilgi, S., Ipbuker, C., Ucar, D., and Sahin, M.: Map Entropy Analysis of Topographic Data Used in Disaster Information Systems, J. Earthq. Eng., 12, 23-36, 2008.

Bittencourt, B. K., Cannabrava, M. P., Del, R., and Trystyn, K.: Evaluating Preparedness and Resilience Initiatives for Distressed Populations Vulnerable to Disasters in Rio de Janeiro, Brazil, IEEE Systems and Information Engineering Design Symposium (SIEDS) Location, Univ. Virginia, Charlottesville, VA, USA, 2013. 
Casagrande, L., Cavallini, P., Frigeri, A., Furieri, A., Marchesini, I., and Neteler, M.: GIS Open Source GRASS GIS, Quantum GIS and Spatialite, Dario Flaccovio Editore, Palermo, 2012.

Chen, D., Daoyi, C., Shams, S., Carmona-Moreno, C., and Leone, A.: Assessment of open source GIS software for water resources management in developing countries, J. Hydro-Environ. Res., 4, 253-264, 2010.

Chen, Y., Yu, J., and Khan, S.: The spatial framework for weight sensitivity analysis in AHP-based multi-criteria decision making, Environ. Model. Softw., 48, 129-140, 2013.

Cimmery, V.: SAGA User Guide, V.2.0.5, available at: http://www. saga-gis.org (last access: 15 May 2014), 2010.

Conrad, O.: SAGA - Entwuf, Funktionsumfang und Anwendung eines Systems für Automatisierte Geowissenschaftliche Analysen, PhD thesis, University of Göttingen, Göttingen, 2007.

Erden, T.: Disaster and Emergency Management Activities by Geospatial Tools with Special Reference to Turkey, Disaster Adv., 5, 29-36, 2012.

Erden, T. and Karaman, H.: Analysis of earthquake parameters to generate hazard maps by integrating AHP and GIS for Küçükçekmece region, Nat. Hazards Earth Syst. Sci., 12, 475483, doi:10.5194/nhess-12-475-2012, 2012.

FEMA: Definitions and terms, Federal Emergency Management Agency, Emmitsburg, MD, USA, 1990.

FGDC: Geospatial Data Model. V.2.7, Federal Geographic Data Committee, Homeland Security Working Group, Washington, USA, 2009.

Gazette of Republic of Turkey: N.5902 law about Organization and Duties of Disaster and Emergency Management Presidency, Republic of Turkey, Ankara, 2009.

GDGIS: Turkey National GIS Institutional Data Requirement Analysis, Republic of Turkey, Ministry of Environment and Urbanization, General Directorate of GIS, V.1.1, edited by: Yomralioglu, T. and Aydinoglu, A. C., Ankara, Turkey, 2012a.

GDGIS: TUCBS Conceptual Data Model Components, Republic of Turkey, Ministry of Environment and Urbanization, General Directorate of GIS, V.1.1, TUCBS Application Rules, edited by: Aydinoglu, A. C., Kara, A., and Yomralioglu, T., Ankara, Turkey, 2012b.

Geonovum: Information Model IMOOV - Conceptual Model, V.1.1, Geonovum, the Netherlands, 2008.

Holcombe, E., Smith, S., and Wright, E.: An integrated approach for evaluating the effectiveness of landslide risk reduction in unplanned communities in the Caribbean, Nat. Hazards, 61, 351385, 2012.

HS: Written Guide for Standard Operating Procedures, Safecom, Dept. of Homeland Security, Washington, D.C., USA, 2008.

Hugentobler, M.: Quantum GIS, in: Encyclopedia of GIS, edited by: Shekhar, S. and Xiong, H., Springer, New York, 935-939, 2008.

Ildir, B.: Distribution of Landslides and Applications concerning Disaster Law in Turkey, in: Proceedings of 2nd National Landslide Symposium, edited by: Onalp, A., Sakarya, Turkey, 1995.

INSPIRE: INSPIRE Data Specification on Natural Risk Zones, Infrastructure for Spatial Information in Europe, Data Specification, Ref. number: D2.8.III.12, v.2.0, Ispra, 2011.

ISO/TC211: ISO 19103 Geographic information - Conceptual schema language, International Standardization Organization, 2005a.
ISO/TC211: ISO 19109 Geographic information - Application Schema Rules, International Standardization Organization, 2005b.

Jaiswal, P. and van Westen, C. J.: Use of quantitative landslide hazard and risk information for local disaster risk reduction along a transportation corridor: a case study from Nilgiri district, India, Nat. Hazards, 65, 887-913, 2013.

Keim, M. E.: Building Human Resilience The Role of Public Health Preparedness and Response As an Adaptation to Climate Change, Am. J. Prevent. Med., 35, 508-516, 2008.

Ko, B. C. and Kwak, S.: Survey of computer vision-based natural disaster warning systems, Opt. Eng., 51, 070901, doi:10.1117/1.OE.51.7.070901, 2012.

Korkmaz, K. A.: Earthquake disaster risk assessment and evaluation for Turkey, Environ. Geol., 57, 307-320, 2009.

Li, Y., Shen, J., Shi, J., Shen, W., Yaung, Y., and Zu, Y.: Multi-model driven collaborative development platform, Adv. Eng. Inform., 22, 328-339, 2008.

Mansouriana, A., Rajabifard, A., Valadan Zoeja, M. J., and Williamson, I.: Using SDI and web-based system to facilitate disaster management, Comput. Geosci., 32, 303-315, 2006.

Molina, M. and Bayarri, S.: A multinational SDI-based system to facilitate disaster risk management in the Andean Community, Comput. Geosci., 37, 1501-1510, 2011.

Muthukumar, M.: GIS based Geosystem response modelling for landslide vulnerability mapping parts of Nilgiris, South India, Disaster Adv., 6, 58-66, 2013.

Neteler, M. and Mitasova, H.: Open Source GIS: A GRASS GIS Approach, 3rd Edn., Springer, New York, 2008.

Neteler, M., Bowman, M. H., Landa, M., and Metz, M.: GRASS GIS: A multi-purpose open source GIS, Environ. Model. Softw., 31, 124-130, 2012.

OASIS: Improving Risk Management, Project Acronym OASIS FP6i Open Advanced System for Disaster and Emergency, Vélizy Villacoublay Cedex, France, 2005.

OGC: OGC Reference Model (ORM), Open Geospatial Consortium Inc., Ref. Number: 08-062r7, v.2.1, Wayland, MA, USA, 2011.

OGC: OGC Geography Markup Language (GML) — Extended schemas and encoding rules, Open Geospatial Consortium Inc., Implementation Standard, Ref. Number: 10-129r1, v.3.3, Wayland, MA, USA, 2012.

ORCHESTRA: Orchestra: an open service architecture for risk management, edited by: Klopfer, M. and Kanellopouos, I., the ORCHESTRA Consortium, Ispra, Italy, 2008.

Saadatseresht, M., Mansourian, A., and Taleai, M.: Evacuation planning using multiobjective evolutionary optimization approach, Eur. J. Operat. Res., 1, 305-314, 2009.

Saaty, T. L.: The Analytical Hierarchy Process, McGraw Hill, New York, 1980.

Saaty, T. L. and Vargas, G. L.: Models, Methods, Concepts, and Applications of the Analytic Hierarchy Process, Kluwer Academic Publisher, Boston, 2001.

Schmitz, O., Karssenberg, D., de Jong, K., and de Kok, J. L.: Map algebra and model algebra for integrated model building, Environ. Model. Softw., 48, 113-128, 2013.

Schneider, P. J. and Schauer, B. A.: HAZUS - Its Development and Its Future, Nat. Hazards Rev., 7, 40-44, 2006. 
Steineger, S. and Hay, G. J.: Free and open source geographic information tools for landscape ecology, Ecol. Inform., 4, 183-195, 2009.

Steiniger, S. and Hunter, A. J. S.: The 2012 free and open source GIS software map - A guide to facilitate research, development, and adoption, Comput. Environ. Urban Syst., 39, 136-150, 2013.

Sudmeier, K. I., Jaboyedoff, M., and Jaquet, S.: Operationalizing "resilience" for disaster risk reduction in mountainous Nepal, Disaster Prevent. Manage., 22, 366-377, 2013.

Teeuw, R. M., Leidig, M., and Saunders, C.: Free or low-cost geoinformatics for disaster management: Uses and availability issues, Environ. Hazards, 12, 112-131, 2013.

UNISDR: UNISDR Terminology on disaster risk reduction, United Nations, Geneva, Switzerland, 2009.

Venkatesan, M., Thangavelu, A., and Prabhavathy, P.: An Improved Bayesian Classification Data mining Method for Early Warning Landslide Susceptibility Model Using GIS, Proceedings Of Seventh International Conference On Bio-Inspired Computing: Theories And Applications (BIC-TA 2012), Madhya Pradesh, India, 2013.
WHO: Coping with Emergencies: WHO Strategies and Approaches to Humanitarian Action, World Health Organization, Geneva, 2005.

Wiles, P., Selvester, K., and Fidalgo, L.: Learning Lessons from Disaster Recovery: The Case of Mozambique, Working Paper Series No. 12, Hazard Management Unit, The World Bank, Washington, D.C., USA, 2005.

Yalcin, A.: Environmental impacts of landslides: a case study from East Black Sea region, Turkey, Environ. Eng. Sci., 24, 821-833, 2007.

Yalcin, A., Reis, S., Aydinoglu, A. C., and Yomralioglu, T.: A GISbased comparative study of frequency ratio, analytical hierarchy process, bivariate statistics and logistics regression methods for landslide susceptibility mapping in Trabzon, NE Turkey, Catena, 85, 274-287, 2011.

Zhang, C., Zhao, T., and Li, W.: Automatic search of geospatial features for disaster and emergency management, Int. J. Appl Earth Obs. Geoinf., 12, 409-418, 2010.

Zlatanova, S., Dilo, A., De Vries, M., and Fichtinger, A.: Models of Dynamic Data For Emergency Response: A Comparative Study, A special joint symposium of ISPRS Technical Commission IV \& AutoCarto, Orlando, Florida, 2010. 